\title{
Trends in online consumption and sharing of content by higher education students
}

\author{
Nídia Morais \\ Escola Superior de \\ Educação \\ Instituto Politécnico \\ de Viseu \\ Viseu, Portugal \\ salome@esev.ipv.pt
}

\author{
Filomena Sobral \\ Escola Superior de \\ Educação \\ Instituto Politécnico \\ de Viseu \\ Viseu, Portugal \\ filomena@esev.ipv.pt
}

\author{
Sónia Ferreira \\ Escola Superior de \\ Educação \\ Instituto Politécnico \\ de Viseu \\ Viseu, Portugal \\ sonia.ferreira@esev.ip
}

\author{
Teresa Gouveia \\ Escola Superior de \\ Educação \\ Instituto Politécnico \\ de Viseu \\ Viseu, Portugal \\ tgouveia@esev.ipv.pt
}

\author{
Cristina Gomes \\ Escola Superior de \\ Educação \\ Instituto Politécnico \\ de Viseu \\ Viseu, Portugal \\ mcagomes@esev.ipv.
}

v.pt

$\underline{\mathrm{pt}}$

\begin{abstract}
This article presents a literature review about media consumption and content sharing on the Internet and is part of a research project that aims to outline and understand practices shared among students of a specific Portuguese higher education institution. Much of the studies found allow us to conclude that students that currently attend higher education are used to multitasking and are active users of online devices, platforms and services in both personal and learning contexts. Research shows that the presence of technology and social media in the daily life of young people is no longer just a growing trend but rather a current fact, which produces intensive and participatory communication dynamics.
\end{abstract}

Keywords- Higher Education, Students, Internet, Content Sharing, Media Consumption

\section{INTRODUCTION}

The development of contemporary societies is no stranger to the rapid global spread of the Internet. This technological infrastructure has assumed an increasing importance in the daily life of individuals and seems to unambiguously shape their perception and representation of the world, the setting of their relationships, the development of their own identity, daily organization, amusement practices and even the way of building knowledge. In the last decades, the various ways of using and sharing information and content among young students of higher education in the 21 st century have changed. In addition to the multiplicity of platforms for communication, technological innovation and the sociocultural metamorphosis itself, the new generations are increasingly multipurpose and multitasking. This puts the Internet at the heart of their communicational experiences, since the Internet is "a virtuality that has become a daily reality" whose appeal "is the possibility of providing each individual the ability to act alone and guide, at their own pace, the way they want to search" [1, p. 14]. The paradigm of consumption and sharing has changed from traditional and linear to online and tentacular.

When taking a closer look at higher education students, digital environments influence how they communicate, participate and produce information and, more specifically, their use and dissemination and/or sharing of content. Recent studies carried out by the Regulatory Authority for Media (ERC) on access and use of the Internet [2, 3] show that it is teenagers and young adults (between 15 and 24 years) who use the Internet more regularly, displaying a movement of growth in this age group, from $94.1 \%$ in 2015 to $96.3 \%$ in 2016 , also showing that the rate of Internet use is higher the higher the level of schooling [2, 4].

In this scenario, and considering the context of a progressive increase in the use of the Internet over the years in Portugal, this article seeks to offer a reading about the practices of content use among the younger population and, in particular, to initiate a study to gauge current trends in the usage and sharing of content on the Internet by students of the Polytechnic Institute of Viseu (IPV). The study presented below aims at understanding the uses that young people make of the Internet, how and for what purposes they use it, as well as knowing the habits of using and sharing content in a network. In this sense, the course of the present literature review characterizes, not only the Millenials' generation, but the devices and platforms they use, too. It also underlines use and digital sharing, leading us to the presentation of the project on usage and Internet content sharing by IPV students to reflect and present data on this reality in order to develop sustained recommendations on the subject matter.

\section{A NEW GENERATION OF STUDENTS IN HIGHER EDUCATION}

In a universe of accelerated digital reconfiguration, where social networks such as Facebook, Twitter or Instagram, among others, are extremely attractive, it is inevitable to note the participation of a large part of the Portuguese population in general, and of the youth in particular, in the multi-media window provided by the Internet. The increase in the supply and demand of digital content, especially among the younger ones, makes us question which multimedia generations are these and what characterizes them. 
As the ERC report [5] suggests, most of them are young people whose rooms as a child were already presented as "cutting-edge technological environments, mainly dominated by screens, by the articulation and convergence between media, co-presence and mobility" (p.156). Increasingly, these 'digital natives' [6] stand out for incorporating three fundamental concepts - autonomy, dominance and speed. This means that "each person can act, without an intermediary, whenever he/she wants, without filter or hierarchy and, more importantly, in real time. You do not have to wait, you act and the result is immediate. This provides a feeling of absolute freedom, and even of power (...)" [7, p.77]. Because these young adults are fully familiar with digital technology (computers and mobile devices) and permanently connected, they assimilate the Internet into their daily life with naturalness, hence "they see the internet as much more than just a revolution" [1, p. 16].

By using the Internet on a regular basis, these generations establish "a variety of uses that are increasingly individual and personalized" [1, p. 17] and seek a path of freedom, control and dominance where each individual can be a producer and receiver of content at an almost immediate speed. The pace is determined by the user, the random course and the instantaneous utilisation. There is a sense of power and leadership. While these young adults are usually alone in front of the screen, they are often part of a huge virtual tribe that shares similar interests and establishes new contacts with ease. Therefore, there seems to be no impression of isolation, but instead the opposite feeling of constant monitoring anywhere and at any time, because the scope of contacts ceases to be face-to-face and local or regional to become global and virtual. In addition, these netizens seem to be quite willing to increase their network of digital friendships.

For these young people, mobile devices have become not only tools of work, but also of leisure, and this is precisely the distinctive aspect that characterizes this generation of Internet users. Their world is connected and mobile. Studying before a screen is all about the pleasure of discovering and sharing their doubts with other students in the cyber world. An interactive and collective intelligence is developed in which young people are able to perform multiple tasks simultaneously and dominate several skills, communicating through the multimedia language where image assumes great preponderance. They are active individuals, emancipated technologically, seduced by the abundance of contents and apparent lack of control. They are part of the "society of screens" [8], mastering techniques of self-promotion and production of their own information, often in collaboration. They make up the "G (Google) generation" [9, p.150] that communicates in a network, creative, participant and actively part of groups in social networks that are not afraid of experimentation. The fact that these new generations develop skills almost intuitively and reveal a desire for personal expression mediated by the screen is exceptional. The fear of exposure is therefore small and the desire for rapid dissemination is a goal.

So, immersed in a network environment, these young social actors materialize the opening to remix and mashup, open source, beta testing and updating [10], which leads to a culture based on openness. On the other hand, "Openness as a fundamental principle associated with production also implies continuous innovation and the ability to surprise" [10, pp. 230231], features that help characterize Generation Y or the socalled Millennials or Echo Boomers.

In terms of age delimitation, this youth is placed in the transition from the phase of adolescence to adulthood, with the end marked by the independence of the family [11]. They are the individuals who were born with the turn of the millennium into a world of technological rationality [12]. According to [13, p.92] "With a view of the world unlike any other, Millennials have grown in years of rapid change, which they have become accustomed to and have learned how to react "and adds that "In a few years, social, economic and technological changes have given the members of this generation priorities and expectations far from previous generations". These juvenile actors are, therefore, protagonists of new practices of sociability and communication and have common behavioural tendencies. Another determining factor is their ability to make choices continuously and get involved in activities they enjoy. Various investigations [14, 15], points out that these young people "are curious, hyperactive, generally unprejudiced, communicative and almost always ambitious" [14, p.4]. In this sense, a new sociocultural and communicational paradigm is evidenced where "social networks and collaborative strategies, as well as the centrifugal and full knowledge that will result from them, will be par excellence the great social link of the 21 st century" [9, p.12].

Therefore, students currently attending higher education are part of a generation that is increasingly involved with technologies than any previous generation [16]. Young people who belong to this Millennial Generation have very different characteristics from previous generations: they have grown up with cable TV, the Internet and mobile phones, are fluent in technology and feel comfortable using it. For them, technology is almost a part of their DNA [17] and they have been creating a whole set of new practices and new habits resulting from an increasingly intensive use of the devices and services that they have at their disposal.

\section{PLATFORMS AND DEVICES FOR USE AND CONTENT SHARING}

The popularity of the Internet has not only increased exponentially, it seems to have irreversibly altered the way content is accessed and appropriated. Part of this appropriation is associated with its usage and sharing across different devices and platforms.

The use of digital devices that allow checking, content sharing and online communication is nowadays an integral part of the life of young people who attend higher education. Of these devices, the mobile phone is emphasised not only in direct communication activities (phone calls, SMS, MMS), but also to carry out activities as diverse as accessing social networks, viewing videos, listening to podcasts, using apps, among many other possibilities. The use of mobile devices allows them to be permanently connected to the real world and to the virtual world and in different contexts, in which one of the questions to be asked is: "where has this generation not used its mobile phone yet?"

These new digital behaviours are due, on the one hand, to the transformation that telecommunication operators have 
placed in terms of broadband and Wi-Fi access, which has allowed the proliferation of Internet access and, on the other hand, the use of more portable, lighter, more powerful and more effective equipment [18]. In this context, a whole new set of possibilities is opened up that allows this generation to take advantage of the benefits and opportunities in terms of progress and innovation associated with the use of Information and Communication Technologies (ICT) in today's society, namely due to their ability to access, produce, and participate in new digital environments as critical and active citizens.

The use of different devices and platforms for media consumption has evidenced the ability of these young people to use various media and perform different tasks simultaneously multitasking. In this regard, a study carried out in 2011 by the Portuguese Advertisers Association (APAN) reveals that more than half of the Portuguese can use various means simultaneously, of which TVs, Internet and mobile phones are highlighted. The most frequent combination is TV and mobile phone (51\%), followed by TV and Internet (19\%). The duo TV and print press, as well as TV and radio, are the preference of about $10 \%$ of the participants. The same study [19] reveals that young people are more likely to give up television than mobile phones and that it would be difficult for them to stop surfing the Internet. However, television continues to be the most comprehensive medium for the Portuguese, being very associated with activities such as news and information (94\%). The use of the Internet is mainly due to the sending and receiving of e-mails (75\%), information and research (64\%) and access to social networks (49\% for young people). The study also highlights the fact that young adults are those who exploit the most important features of mobile phones, such as sending and receiving SMS (97\%), taking pictures (45\%), using the alarm options (42\%), listening to music (40\%), exchanging MMS (30\%), using the calculator (24\%), playing games $(23 \%)$ and listening to the radio $(17 \%)$.

As for the most used digital devices, "the most common is the portable computer, followed by the mobile device (tablet or smartphone) and finally the fixed computer" [18, p. 5]. Laptops are the most widely used devices in Internet access, followed by smartphones and tablets in terms of mobile alternatives. This study reveals a similar trend to the study conducted by APAN, concluding that a large part of young people $(58 \%)$ are multitasking because they carry out several activities simultaneously, such as surfing the Internet while watching $\mathrm{TV}$, although they spend more time surfing the Internet (about $4.2 \mathrm{~h}-2.1 \mathrm{~h}$ on the laptop, $1.3 \mathrm{~h}$ on the mobile phone and $1.5 \mathrm{~h}$ on the fixed computer).

ERC's study on Public and Media Consumption in Portugal [2] also confirms that in terms of devices, the computer is the most used to access the Internet $(96 \%)$, followed by the smartphone (51\%) and finally the tablet (19\%).

In the USA, a research carried out close to the Millennial's generation [20] reveals that young people between the ages of 18 and 29 are enthusiastic about using technology, particularly the Internet and mobile phones, which to them are more than just sources of information and entertainment. Instead, they are a whole new ecosystem for the construction of their personal identity and social life. In fact, in terms of the devices they use, the mobile phone is like an extension of their own 'self', which allows them to be permanently connected through Wi-Fi networks, which translates into new and more varied behaviours such as the interaction through social networks, viewing and sharing online videos, sending and receiving messages, among others.

According to the same study [20], most Millennials (74\%) say using technology makes their lives easier, helps them spend their time more efficiently (56\%), as they believe technology brings people closer rather than making them more isolated $(52 \%)$.

Consequently, it is a generation that has grown in digital environments and lives in a culture mediated by the mobile phone, characterized by mobility and also by the pressure of always being available to receive and reply to messages, encouraging young people to be connected "all the time and anywhere" [21]. Indeed, the most privileged devices are the most "easily transportable, with screens of dimensions that provide privacy" [21, p. 24]. Among them, mobile phones and the smartphone for Internet access are noticeable, allowing them to carry out activities as diverse as listening to music, visiting social networks, watching videos, using instant messaging applications and searching information, among others. The same investigation also concluded that young people who own or have access to a smartphone or tablet are more likely to download applications, connect to wireless networks, and update their profiles on social networks, photos or even to make a short video to share online [21]. The Frye Institute's Survey [22] concludes that, on average, every young person in westernized society will have:

- spent 10,000 hours playing computer;

- watched 20,000 hours of television;

- used their mobile phone for many thousands of hours;

- and received 200,000 emails.

These figures could undoubtedly relate to a young Portuguese. In actual fact, according to the Survey on the Use of Information and Communication Technologies by households carried out by the National Statistical Institute (INE), the vast majority of Portuguese households have access to the Internet at home, mostly with broadband connection (70\%). The younger age groups (up to 44 years of age) report a more frequent use of computers, the Internet and e-commerce [23]. The results of this survey also reveal that "it is the students who use the most information and communication technologies: all students use computers and the Internet, and $38 \%$ have placed orders through the internet" [23, p. 4]. The data also allow us to conclude that "Internet access outside the home and the workplace through portable equipment is carried out by about two-thirds $(66 \%)$ of Internet users, with the mobile phone or smartphone being the most used (by $60 \%$ of Internet users) to access the Internet on the move" [23, p. 6].

A more recent study carried out by INE [24] reveals that, in 2016, about $23 \%$ of the Portuguese had already placed orders through the Internet, being a practice more frequent for those who have completed higher education (53\%) and for those who are aged between 25 and 34 years (44\%). As for the most used 
equipment to access the Internet, the most significant are the mobile phone/smartphone (78\%) and the portable computer $(73 \%)$, and the vast majority of users $(72 \%)$ access the Internet during mobility. This study also indicates that the use of the Internet is a widespread practice among students, covering almost all (99\%) of young people between 16 and 24 years old and those who have completed higher education (98\%).

\section{TRENDS IN USE AND CONTENT SHARING}

The Internet has long been confined to mere search and individual use of content. Today, everybody can, in a participatory and collaborative Internet where social networks and websites abound, create, use and share information. In this sense, "the Web is no longer a one-way street where someone controls the content. Anyone can control content (...)" [25, p. $8]$.

Despite the fact that the Internet has expanded the possibilities of sharing digital content and the consequent debate on digital piracy, in this text the term sharing is treated in the broadest sense of dissemination/transmission of free content. Effectively, the Internet hosts a multitude of platforms for interpersonal communication and/or social transmission of information and/or content. Facebook, YouTube, E-Mail and Twitter are just a few examples. In a study on network participation [26], the author argues that "social media tools that have emerged in this generation of the Internet and which present models of publication, sharing and communication oriented to a collective structure, have transformed the way people communicate and interact online" [p. 133]. At a national level, this statement is in some way corroborated by the results of a Survey regarding the Use of Information and Communication Technologies by Families, which reveal that the sharing of content created by Internet users in Portugal is an activity which is emphasised, above the EU average in 2015 [24]. We are therefore witnessing the so-called social web, which has led to changes both in terms of production and in the use of information and/or content. Regarding these changes, millions of information units are shared on Facebook every day, including short sentences, articles, photos and audio and video clips [27]. These numbers confirm the potential of social media as privileged spaces for sharing-oriented interaction practices. The 2010 report, by the Pew Research Centre Internet \& American Life Project, has already indicated that these practices would last, because Millennials makes online social networking a lifelong habit [28]. In this study on the future impact of the Internet, $67 \%$ of respondents agreed with the idea that Generation Y will continue to play an active role in networked environments and that, despite having more responsibilities, they will continue to display enthusiasm by the broad sharing of online information. The same report suggests that for Millennials, the benefits of sharing information/content online outweigh privacy concerns. New definitions of private and public information in the network society thus appear to be imposed, which means that as the population ages, this generation may change the type of personal information it makes available, but the age factor will not affect their motivation for sharing content [28].

Effectively, the domains of use that the Internet users make of the global network have been multiplying [29]. The Internet is increasingly becoming a space of sociability and communication practices that generate contexts that, in turn, highlight activities such as sharing content. The same authors also point out a differentiation in terms of age with respect to Internet usage domains, stating that "when compared to younger individuals, older generations seem to have a more passive use of the internet, preferring search to the creation or sharing of content " [29, p. 99].

Also, the user experience promoted by the portability of Internet access devices, as well as the availability of various applications and technological developments that enable touch screen interfaces, seem to have an impact on the more direct and instantaneous way of accessing information and/or content and to promote its dissemination [29].

In terms of content usage and sharing, according to the report The New Dynamics of Audio-visual Consumption in Portugal carried out by ERC, among regular Internet users, the use of instant messaging programs (68\%), search for entertainment content $(62.8 \%)$ and Internet telephone calls $(50 \%)$ are the main activities carried out [3]. The visualization of videos produced by both amateurs and professionals also appears as a practice of more than half of the participants $(58.9 \%$ and $57.5 \%)$. With regard to the consumption of traditional media - newspapers, magazines, radio and television - on the Internet, $53.6 \%$ regularly access newspaper and magazine content, $22.7 \%$ listen to the radio and $21.7 \%$ use television content. Data from the same study also reveal that $30.4 \%$ of the respondents read blogs, $28.4 \%$ play online games and $25 \%$ use professional social networks.

Specifically, in the age group of 15 to 24 years, and according to the study Leisure, Employment, Mobility and Politics: Situations and Attitudes of the Portuguese Youth in a Comparative Perspective [30], consumption reality is clearly different. The use of social networks emerges, effectively, as the most accomplished activity by young people. In fact, $91.9 \%$ of the participants use the Internet daily for this purpose. Following are some activities like sending and receiving emails, searching for information about events, products or services, using Skype, playing games and listening to music [30]. The same study relates the purposes of Internet use on behalf of young people aged 15 to 34 with some sociographic variables. The results suggest that there are uses that differ in terms of the profile of those who use it.

As for gender, there are activities carried out more frequently by the female than by the male population, such as research and reading activities $(63.7 \%$ vs. $58.8 \%)$, reading newspaper articles (37.5\% vs. $31.1 \%)$ and, especially, in reading blogs $(28.9 \%$ vs. $19.8 \%)$. On the other hand, men stand out in the consumption of playful content, specifically in the use of social networks $(88.2 \%$ vs. $88.1 \%)$, playing computer games $(61.8 \%$ vs. $45.7 \%)$, downloading movies, music or television series $(40.7 \%$ vs. $35.6 \%)$ and watching movies or television shows in real time (35.8\% vs. $28.9 \%)$.

A similar trend is advanced by data obtained provided by the European School Survey Project on Alcohol and Other Drugs [31] revealing that Portuguese teenagers use the Internet six days a week and the activity carried out on the Internet is the use of social networks $(78 \%)$. In fact, this data 
corroborates the results of the previous study in that male participants spend more time downloading or listening to music, and watching movies and videos. In turn, the female gender is more active in social networks than the male gender (80\% vs. $60 \%)$. In total, 96,000 European students aged between 15 and 16 were surveyed [31].

As for the socioeconomic situation, the results presented in the study by [30] show that the younger individuals reported 'living comfortably with their current income' who present higher values for the various activities developed on the Internet, except with the purpose of playing computer games, when compared to the categories 'lives reasonably with current income' and 'lives with current income with much difficulty." The latter were those who presented lower values of use, except for the use of social networks, only lower when compared to the category 'lives comfortably with current income' (92.1\% and 93.2\%, respectively).

From the foregoing, it is certain that the network environments emerge new social practices, and the contents are elements that promote habits of sharing and use that are fundamental for the perception of online behaviour. In this context, it seems important to develop research to identify the uses that higher education students make of content available online, whether in personal and/or learning contexts.

\section{ONGOING PROJECT}

Based on the literature review, it is relevant to develop a project that contributes to the understanding of the uses that the students of higher education, in particular those of the Polytechnic Institute of Viseu, make of the contents available on the Internet. More specifically, the project aims to identify what type of content they use and share online, as well as to gather qualified information about this reality that makes it possible to develop evidence-based recommendations to maximize effective communication with current and potential future students.

In general, the present study, which is still under development, aims to:

- Identify the content used by the students of the different IPV schools;

- Understand for what purposes and in what contexts the content is viewed and shared;

- Identify the benefits and main problems of content consumption and sharing.

Methodologically, this is a case study, mobilizing a mixed approach that favours the use of quantitative methods for data collection, by applying a questionnaire to a significant sample of IPV students, coupled with qualitative methods through the development of interviews and the execution of focus groups with some students that represent the diversity of the educational fields of the IPV that will later be interpreted in a qualitative way. The phases that are identified in the scope of this project are: i) Realization of the literature review; ii) Construction and validation of data collection instruments (questionnaire, semi-structured interview script and guide for focus groups); iii) Data collection; iv) Analysis of results; v) Proposal of guidelines.

It is hoped that the results of this research may contribute to the identification of trends regarding the most used and shared contents of the IPV students. In this sense, the results achieved may serve as a reference for making more informed decisions about the IPV's communication and information dissemination practices with its student community. It may also be useful in the development of institutional and pedagogical communication strategies that aim at the capture of new students and the proposal of other cycles of study.

\section{FINAL CONSIDERATIONS}

The literature review aimed, generally, to reflect on the characteristics and/or factors that configure the way the relationship with information occurs in digital environments. Some trends are revealed in the context of the consumption and sharing of contents through the Internet, and the aforementioned studies show in the majority a strong presence of technology and social media in the daily life of young people, which gives them a more intensive and participatory communicational dynamic. In this context of ordinary digital technologies, the so-called Millennial Generation stands out, with multitasking features and available for an active use of devices, platforms and online services on both a personal and learning level. Therefore, in this generation of the Internet, the practices of sociability and communication are understood as two distinct things, and so it is necessary to analyse them in order to obtain detailed data about their technological appropriation of online content.

The trends observed with regard to consumption and sharing are the basis for studies that will consolidate knowledge in this specific area. Thus, it is assumed that the development of a project in the field of higher education, mainly in an institution such as the IPV, contributes to the achievement of concrete and effective communication actions, because they are based on the parameters resulting from the perception of the students' online practices.

\section{ACKNOWLEDGMENTS}

This work is financed by national funds through FCT Fundação para a Ciência e Tecnologia, I.P., under the project UID/Multi/04016/2016. Furthermore we would like to thank the Instituto Politécnico de Viseu and CI\&DETS for their support.

\section{REFERENCES}

[1] J. Piette, "Os jovens e a internet: De que "público" se trata?" in J. C. Abrantes (Eds), Ecrãs em mudança: Dos jovens na internet ao provedor da televisão, Lisboa: Livros Horizonte, 2006, pp. 13-24.

[2] Entidade Reguladora para a Comunicação Social. (2017, March 22). Públicos e consumos de média - o consumo de notícias e as plataformas digitais em Portugal e em mais dez países [online]. Available: http://www.erc.pt/download/YToyOntzOjg6ImZpY2hlaXJvIjtzOjM4OiJ tZWRpYS9lc3R1ZG9zL29iamVjdG9fb2ZmbGluZS82OS4xLnBkZiI7c zo2OiJ0aXR1bG8iO3M6MzU6ImVzdHVkby1wdWJsaWNvcy11LWNv bnN1bW9zLWR1LW11ZG1hIjt9/estudo-publicos-e-consumos-de-media

[3] Entidade Reguladora para a Comunicação Social. (2017, March 22). As novas dinâmicas do consumo audiovisual em Portugal [online]. 
Available:

http://www.erc.pt/documentos/Estudos/ConsumoAVemPT/ERC2016 A sNovasDinamicasConsumoAudioVisuais web/assets/downloads/ERC20 16 AsNovasDinamicasConsumoAudioVisuais.pdf

[4] OberCom. (2017, April 5). A Internet em Portugal. Sociedade em Rede 2014 [online]. Available: https://obercom.pt/wpcontent/uploads/2016/06/A-Internet-em-Portugal-Sociedade-em-Rede2014.pdf

[5] Entidade Reguladora para a Comunicação Social. (2017, February 17). Os públicos dos meios de comunicação social portugueses [online]. Availabel:

http://www.erc.pt/download/YToyOntzOjg6ImZpY2hlaXJvIjtzOjM4OiJ tZWRpYS91c3R1ZG9zL29iamVjdG9fb2ZmbGluZS8zMi44LnBkZiI7cz o2OiJ0aXR1bG8iO3M6NTA6ImVzdHVkby1kZS1yZWNlcGNhby1kb3 MtbWVpb3MtZGUtY29tdW5pY2FjYW8tc29jaWFsIjt9/estudo-derecepcao-dos-meios-de-comunicacao-social

[6] M. Prensky, "Digital natives, digital immigrants Part 1", On the Horizon, vol. 9(5), 2001, pp. 1-6.

[7] D. Wolton, “E depois da internet?", Lisboa: Difel, 2000.

[8] G. Cardoso, “A Sociedade dos ecrãs”, Lisboa: Tinta-da-China, 2013.

[9] F. R. Cádima, "A televisão, o digital e a cultura participativa", Lisboa: Média XXI, 2011

[10] G. Cardoso and P. Jacobetty, "Surfando a crise: Culturas de pertença e mudança social em rede", in Cardoso G. (Eds.), A Sociedade dos ecrãs, Lisboa: Tinta-da-China, 2013, pp. 195-236.

[11] C. Martins, "Geração digital, geração net, Millennials, geração Y: refletindo sobre a relação entre as juventudes e as tecnologias digitais", Diálogo, vol. 29, 2015, pp. 141-151.

[12] R. Tomaz, "A geração dos Millennials e as novas possibilidades de subjetivação", Revista Communicare, vol. 13, 2013, pp. 99-110.

[13] A. F. Miguel, "As roupas que falam - dos e para os millennials portugueses", Master Dissertation in Comunicação e Imagem, Lisboa: Instituto de Arte, Design e Empresa - Universitário, 2015.

[14] R. Silva et al., "Motivação da geração y no trabalho", in Proceedings of the Congresso Internacional de Administração - Gestão Estratégica: Empreendedorismo e Sustentabilidade, Brasil, 2013, pp. 1-12.

[15] S. Oliveira, "Geração Y: ser potencial ou ser talento? Faça por merecer", São Paulo: Integrare, 2011.

[16] H. Nielsen. (2017 April 21). Mobile Youth Around the World [online]. Available: http://www.nielsen.com/us/en/insights/reports/2010/mobileyouth-around-the-world.html

[17] H. Nielsen. (2017 April 21). Millennials: Technology = Socia Connection [online]. Avialable: http://www.nielsen.com/us/en/insights/news/2014/millennialstechnology socialconnection.html

[18] A. Pires, "O admirável mundo novo", in M. et al. (Eds.), Um dia das nossas vidas na internet - Estudo de hábitos digitais dos portugueses,
Lisboa: Nova Expressão - Planeamento de Media e Publicidade, 2015, pp. 4-13.

[19] Associação Portuguesa de Anunciantes. (2017 January 20). Comunicar na era da informação. Que mudanças no consumo de media em Portugal? Estudos e Questionários [online]. Avialable: http://www.apan.pt/conhecimento/estudos-questionarios/

[20] P. Taylor and S. Keeter. (2017, February 2). MILLENNIALS - A Portrait of Generation Next - Confident. Connected. Open to Change [online]. Available: http://www.pewresearch.org

[21] C. Ponte, "As crianças e os jovens crescendo em tempos digitais com os média digitais", in T. Gonçalves (Ed.), Digital Media Portugal - ERC 2015, pp.15-26.

[22] Frye Institute. (2017 January 20). The "Net Generation:" Implications for Libraries and Higher Education [online]. Available: http://www.orbiscascade.org/council/c0510/Frye.ppt

[23] Instituto Nacional de Estatística. (2017, March 22). Sociedade da Informação e do Conhecimento - Inquérito à Utilização de Tecnologias da Informação e da Comunicação pelas Famílias 2015 [online]. Available:

https://www.ine.pt/xportal/xmain?xpid=INE\&xpgid=ine destaques\&DE STAQUESdest boui $=224732374 \& D E S T A Q U E S m o d o=2$

[24] Instituto Nacional de Estatística. (2017, March 22). Sociedade da Informação e do Conhecimento - Inquérito à Utilização de Tecnologias da Informação e da Comunicação pelas Famílias 2016 [online]. Available:

https://www.ine.pt/xportal/xmain?xpid=INE\&xpgid=ine destaques\&DE STAQUESdest boui $=250254698 \& D E S T A Q U E S m o d o=2$

[25] G. Solomon and L. Schrum, "Web 2.0: New tools, new schools", Washington: International Society for Technology in Education, 2007.

[26] I. Amaral, "Participação em rede: do utilizador ao "consumidor 2.0" e ao "prosumer", Comunicação e Sociedade, vol. 22, 2012, pp. 131-147.

[27] W. Ma and A. Chan, "Knowledge sharing and social media: Altruism, perceived online attachment motivation, and perceived online relationship commitment", in Computers In Human Behavior, vol. 39, 2014, pp. 51-58

[28] J. Anderson and L. Rainie. (2017 April 21). Millennials will make online sharing in networks a lifelong habit. Reports of Pew Research Center's Internet \& American Life Project [online]. Available: http://pewresearch.org/millennials/

[29] A. Costa et al., "A sociedade em rede em Portugal", Coimbra: Almedina, 2015.

[30] M. Lobo at al., "Lazer, Emprego, Mobilidade e Política: Situações e Atitudes dos Jovens Portugueses numa Perspetiva Comparada”, Lisboa: Instituto de Ciências Sociais da Universidade de Lisboa, 2015.

[31] European School Survey Project on Alcohol and Other Drugs. (2017, February 17). The 2015 ESPAD Report [online]. Available: http://www.espad.org/report/home. 